\title{
Air leakage in Catalan dwellings: Developing an airtightness model and leakage airflow predictions
}

\author{
María I. Montoya ${ }^{\mathrm{a}}$, Elsa Pastor ${ }^{\mathrm{a}}$, F. Rémi Carrié ${ }^{\mathrm{b}}$, Gaelle Guyot ${ }^{\mathrm{b}}$, Eulàlia Planas ${ }^{\mathrm{a}, *}$ \\ ${ }^{a}$ Centre d'Estudis de Risc Tecnològic (CERTEC), Departament d'Enginyeria Química, Universitat Politècnica de Catalunya, ETSEIB, Diagonal 647, Pav. G, planta 1, \\ 08028 Barcelona, Spain \\ ${ }^{\mathrm{b}}$ Centre d'Etudes Techniques de l'Equipement de Lyon (CETE), 46 rue Saint Théobald, F-38081 L'Isle d'Abeau Cedex, France
}

\section{A R T I C L E I N F O}

\section{Article history:}

Received 19 October 2009

Received in revised form

9 December 2009

Accepted 11 December 2009

\section{Keywords:}

Airtightness

Infiltration

Air exchange rate

Residential dwellings

\begin{abstract}
A B S T R A C T
In this study we estimate the air leakage distribution of single-family dwellings in Catalonia and use a statistical analysis of an airtightness database for single-family dwellings in France to identify the building characteristics that have the greatest influence on airtightness. The most significant variables are found to be the structure type, the floor area, the age of the building, the number of stories and the insulation type. A multiple linear regression technique is then applied to establish a predictive model for deriving an estimated value of airtightness from these characteristics. To estimate the infiltration airflow, a stochastic simulation of the building characteristics was performed per census tract using real data on the distributions of building variables taken from the census information. The model is then applied to determine the power law coefficient and the airtightness distribution. The predicted flow coefficients are combined with the AIM-2 model and given meteorological conditions to determine the infiltration airflow. Two sets of meteorological conditions are considered: average conditions and extreme conditions for each season.
\end{abstract}

(c) 2009 Elsevier Ltd. All rights reserved.

\section{Introduction}

This paper forms part of a general study focused on the assessment of shelter-in-place effectiveness of Catalan dwellings in the event of a toxic gas release. Catalonia is a highly industrialized region in the north-east of Spain in which 180 companies are regulated by the Seveso II Directive [1]. In a shelter-in-place situation, air infiltration is one of the variables with the greatest influence on shelter-in-place effectiveness, as discussed by Chan et al. [2] and Montoya et al. [3], because it conditions the speed of toxic gas inflow and therefore the indoor gas concentration.

Air infiltration flow refers to the flow of outdoor air through envelope leaks (i.e. through non-intentional openings) generated by meteorological conditions. Therefore, this flow depends on the airtightness of the building and the pressure difference between outdoors and indoors. The pressure difference is a function of the stack effect and the wind, whereas the airtightness depends on the envelope leakage characteristics and is therefore independent of weather conditions [4]. However, no experimental data on air

\footnotetext{
* Corresponding author. Present address: ETSEIB, Diagonal 647, Pav. G, planta 1, 08028 Barcelona, Spain. Tel.: +34 934011736; fax: +34 934017150.

E-mail address: eulalia.planas@upc.edu (E. Planas).
}

infiltration exchange rate $(A C H)$ or airtightness is available for Catalan dwellings.

Air infiltration in single-family dwellings has become a popular research area over the last three decades, because it greatly influences the energy performance of buildings and indoor air quality. Recently, European legislation concerning the energy performance of buildings has become more demanding. Possible solutions to meet the new requirements, as described by Erhorn et al. [5], are based not only on additional insulation or more effective building systems, but also on reducing infiltration losses by improving building airtightness. Air infiltration also affects indoor air quality and, since single-family dwellings in southern Europe are not usually fitted with mechanical ventilation systems, infiltration is the only means of pollutant transport between outdoors and indoors when all intentional openings are closed. Consequently, air infiltration conditions the inflow of outdoor common pollutants and toxic substances in the event of an accidental release and influences the outflow and retention of contaminants of indoor origin such as tobacco smoke.

Consequently, as expressed by Sherman [6], there is a need to determine the real distribution of building stock airtightness and the resulting magnitude of the air infiltration flow. This information is essential for characterizing the status of the current building stock and for establishing a foundation for future research into aspects 


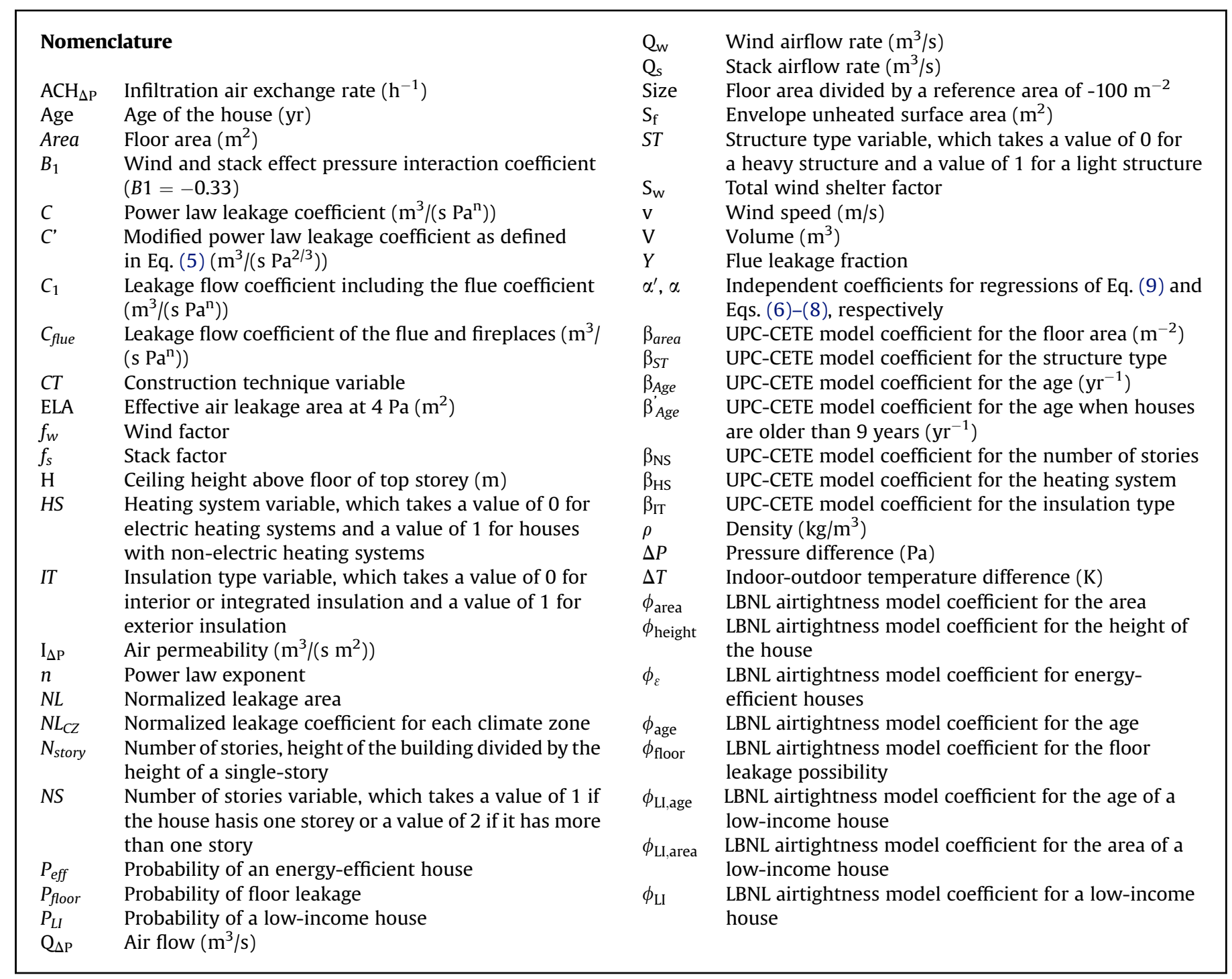

such as ventilation efficiency, energy performance of buildings, indoor air quality, and the effectiveness of shelter-in-place as a protective measure in the event of an accidental toxic release.

The infiltration flow or infiltration air exchange rate in singlefamily dwellings is usually determined empirically or semiempirically. Empirical values are obtained using a tracer gas dilution technique, as described in the ASTM standard E741-00 [7], although it should be noted that the results are specific to the prevailing meteorological conditions during the test period. In contrast, the semi-empirical method provides estimated values of $A C H$ under different meteorological conditions; this approach consists in determining the envelope airtightness and then applying a ventilation model to estimate the infiltration airflow as a function of the meteorological conditions. Since a single-family dwelling is usually considered to be a single zone volume [4], single-zone models such as the LBL model [8] or the AIM- 2 model [9] can be used to estimate the $A C H$ as a function of the airtightness, the indoor-outdoor temperature difference and the wind speed.

Increased research efforts in recent years have improved our understanding of infiltration air exchange rate and airtightness. Following the 1973 oil crisis, researchers in Germany and the Netherlands carried out a series of experimental $\mathrm{ACH}$ measurements as a step towards reducing ventilation heat losses [10]. The results of this research showed that $A C H$ varied from 0.3 to $0.7 \mathrm{~h}^{-1}$ for high buildings and from 0.5 to $2.0 \mathrm{~h}^{-1}$ for low buildings, taking into account both multifamily and single-family dwellings. Two empirical expressions were proposed for estimating the $A C H$ as a function of wind speed. Engelmann [11] examined previous $A C H$ measurements and developed empirical isopleths to estimate $A C H$ as a function of wind speed and temperature difference, for closed homes of modern construction with good insulation and for older homes with poor insulation. Later studies focused on qualitative and quantitative analysis of available airtightness and $A C H$ measurements to determine distributions and trends. Murray \& Burmaster [12] and Angell et al. [13] studied the $A C H$ distribution of single-family dwellings in the USA as a function of climatic region and season. Sherman \& Dickerhoff [14] analyzed the single-family dwellings airtightness dataset compiled by the Lawrence Berkeley National Laboratory (LBNL) to determine the influence of basement type, age, presence of a duct system, number of stories and participation in weatherization assistance programs on the normalized leakage area (NL). Orme et al. [15] analyzed the Air Infiltration and Ventilation Centre (AIVC) database, which contains airtightness data for buildings in different countries. They examined the behavior of $A C H$ at 50 Pa over a wide range of dwellings with different occupancy modes, years of construction and 
construction techniques. They concluded that multifamily dwellings are more airtight than single-family dwellings, that construction type and year of construction have a strong influence on airtightness (new constructions are more airtight), and that dwellings located in severe climatic regions are more airtight. Orme et al. [15] proposed a series of worksheets for estimating the value of $A C H$ at 50 Pa depending on the building type, the construction techniques and the height of the building (low-rise or high-rise building). France is the leading nation in the southwest Europe research in this field, in which researchers have typically focused on determining the main air leakage paths and exploring airtightness patterns for different construction types (masonry or timber frame), occupancy modes (single or multifamily dwellings) and insulation types (interior, integrated and exterior thermal insulation). Litvak et al. [16,17] and Carrié et al. [18] concluded that multifamily dwellings were more airtight than single-family dwellings, that masonry buildings were more airtight than those with timber frames, and that no trends were observed for thermal insulation types. A detailed survey on airtightness measurement practices and state-of-the-art research in this field can be found in Sherman \& Chan [19].

Statistical analysis of air leakage datasets for single-family dwellings has also been performed recently by the LBNL $[20,21]$. These analyses deal with the development of a predictive model for estimating the NL of dwellings in the USA as a function of house characteristics. The model developed by Chan et al. [20] takes into account as predictor variables the year of construction and the floor area for three types of houses: low-income houses, energy program houses and conventional houses. The model developed later by McWilliams \& Jung [21] was based on a larger dataset and predicts the value of NL as a function of climate zone, building age, floor area, building height, floor type, and energyefficiency and low-income classifications (LBNL airtightness model). Although these models cannot provide accurate predictions for individual cases, they produce reasonable estimations of leakage distributions for populations of houses [20,6].

If information on the required variables is available, the $A C H$ of dwellings in Catalonia can, in theory, be estimated using the TNO empirical equations or the LBNL airtightness model; however, construction techniques and materials and the climate regions found in the Netherlands or the USA differ significantly from their equivalents in Catalonia. Consequently, air leakage data for French dwellings is essential to our research due to the similarities between French and Catalan construction types and climate regions. We developed a predictive model for estimating airtightness as a function of house characteristics, using data from the air leakage database for French single-family dwellings compiled by the Centre d'Études Techniques de L'Équipement (CETE) in Lyon. The model was used to estimate the airtightness distribution of single-family dwellings in Catalonia, and the results were integrated into the AIM-2 single zone ventilation model [9] to predict the $A C H$ distribution. We then compared the $A C H$ distributions with the results obtained using the LBNL airtightness model [21] and the TNO empirical equations [10]. An overall picture of the approach followed in this work is shown in the diagram of Fig. 1.

\section{Database analysis}

\subsection{Description of the database}

The envelope airtightness of residential dwellings is usually measured with a pressurization technique [22], which consists in pressurizing the house envelope with a large fan or blower fitted in a door or a window and measuring the airflow required to maintain a certain indoor-outdoor pressure difference. Buildings with a higher degree of leakage require more airflow to maintain the pressure difference. Several pressure differences and airflow measurements are taken, and the dataset is then regressed to fit the power law equation (Eq. (1)) and determine the power law coefficient $(C)$ and power law exponent $(n)$.

$Q=C \cdot(\Delta P)^{n}$

The exponent $n$ can take a value in the range of $0.5-1$ depending on the airflow pattern, which is characterized as laminar (close to 1 ) or turbulent (close to 0.5) [4]. For residential buildings this coefficient is usually in the range $0.6-0.7$, and a typical value is $2 /$ 3 [23]. These power law constants can be used in single zone infiltration models like the AIM-2 model to estimate the infiltration airflow as a function of wind speed and indoor-outdoor temperature difference.

The CETE de Lyon database contains 483 single-family dwelling pressurization measurements taken in a series of studies from 1983 onwards using the pressurization method. The measurements were used to characterize the general envelope airtightness of residential buildings throughout France by identifying the most important leakage paths and possible trends linked to specific structures or materials. The database was found to contain several measurements for the same house (i.e. from tests carried out before and after improvements, before and after construction was completed, etc.), so the data were reviewed and only the measurement that most accurately reflected the envelope airtightness of each house was used. Two hundred and fifty-one measurements were selected for the analysis.

The database contains several fields for each measurement, which describe the characteristics of the dwelling, the exact nature of the test, and the results obtained, as shown in Table 1. The $A C H$, calculated as shown in Eq. (2), relates the airflow at a given pressure difference to the volume of the dwelling. In addition to the $A C H$ at 10 and $50 \mathrm{~Pa}$, the air permeability at $4 \mathrm{~Pa}$ was also reported in the results because it is the airtightness indicator stipulated in French regulations. The air permeability, as defined by Eq. (3), denotes the ratio between the air leakage rate and the envelope unheated surface area, which is the surface that separates the indoor heated volume from the outdoor air and unheated spaces [17].

$A C H_{\Delta P}=Q_{\Delta P} / V$

$I_{\Delta P}=Q_{\Delta P} / S_{f}$

Airtightness is represented in terms of $C$ and $n$. Since $n$ had a small range of variability and more than $90 \%$ of the values were in the range $0.58-0.7$, the value of $n$ was fixed at $2 / 3$, which is the typical value for a residential building, as mentioned above. However, to reduce the error implicit in applying a constant $n$, a new parameter, $C^{\prime}$, was introduced. This parameter takes into account the effect of $C$ and $n$ on the airflow for a given pressure difference. As shown in Eq. (4), the value of $C^{\prime}$ is the value of $C$ that, when applied with an $n$ of $2 / 3$ and at a given pressure difference, would produce the same airflow as the real values. The reference pressure difference $\left(\Delta P_{r}\right)$ under typical meteorological conditions, commonly used in the USA and southern Europe, is $4 \mathrm{~Pa}[4,18]$. Therefore, $C^{\prime}$ was defined taking $4 \mathrm{~Pa}$ as the reference pressure difference (Eq. (5)).

$Q=C \cdot\left(\Delta P_{r}\right)^{n}=C^{\prime}\left(\Delta P_{r}\right)^{2 / 3}$

$C^{\prime}=C \cdot(4)^{n-2 / 3}$

As shown in Fig. 2, values of $C$ and $C^{\prime}$ fit a log-normal distribution and show similar behavior, which was expected because most values of $n$ 


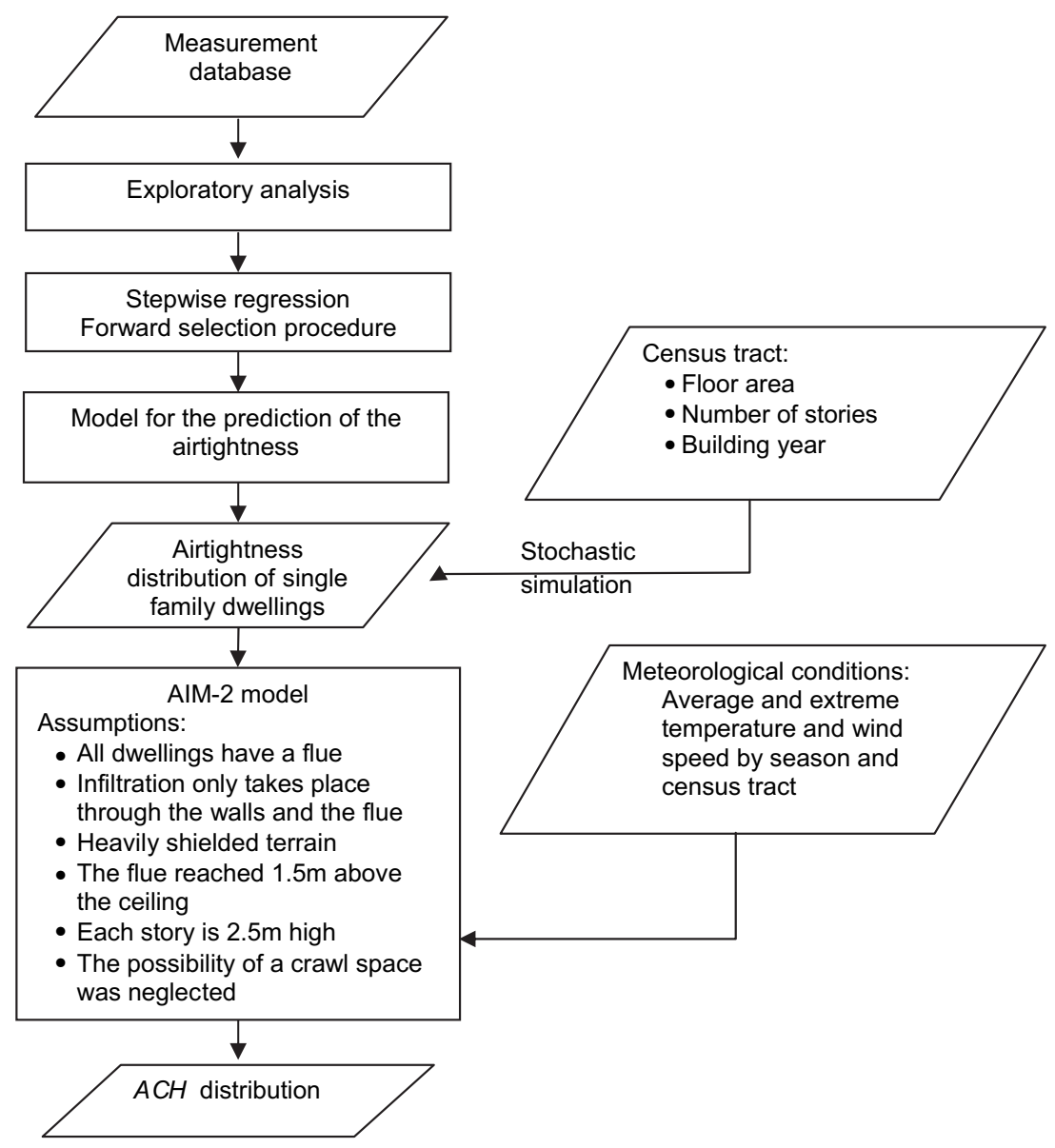

Fig. 1. Flow chart of the methodology used.

lay around the fixed value of $2 / 3$. Therefore, the natural logarithm of $C^{\prime}\left(\operatorname{Ln}\left(C^{\prime}\right)\right)$ was used in the data analysis, instead of $C^{\prime}$ itself.

\subsubsection{Variables considered}

The building features considered to influence airtightness for the purposes of the study are the dwelling characteristics shown in the dataset (see Table 1). The building material and construction

Table 1

Database information.

\begin{tabular}{ll}
\hline Test features & Date of test \\
& Number of test \\
& Method used (pressurization, depressurization) \\
& Specific features of test (state of openings) \\
Dwelling characteristics & Building material \\
& Construction type \\
& Heating system \\
& Heated volume \\
& Envelope unheated surface area \\
& Number of stories \\
& Location \\
Insulation type & Year of construction \\
& Floor area \\
& $C$ \\
Results & $n$ \\
& $A C H$ at 10 Pa $\left(A C H_{10}\right)$ \\
& $A C H$ at 50 Pa $\left(A C H_{50}\right)$ \\
& Air permeability at $4 \mathrm{~Pa}\left(I_{4}\right)$ \\
\hline
\end{tabular}

technique characterize the structure type of the dwelling, which is defined as either light or heavy. Light-structured dwellings, which are generally accepted to be leakier than those with a heavy structure [16], comprise houses constructed with wood or steel, and within a frame structure. Heavy-structured dwellings are those built with other materials such as concrete, cellular concrete, fired clay, masonry and/or within a structural wall. For this variable, $68.9 \%$ of the dwellings considered had a heavy structure, $21.5 \%$ had a light structure, and 9.6\% were not defined in the data. The prevalence of heavy structures reflects a general trend in single-family dwelling construction stock in France. The insulation variable covers three types of insulation: exterior insulation (4.4\%), interior insulation (34.3\%) and integrated insulation (17.6\%). No data were available for $43.7 \%$ of cases. The heating system variable refers to the nature of the heating source. Five types of heating systems were identified in the database: electric (25.5\%), gas (18\%), heating pump $(0.4 \%)$, fuel oil (2.4\%) and other (5.1\%). No data were available for $48.6 \%$ of cases. Since few dwellings had heating pump, fuel oil, gas and other heating systems, we considered only two options for this variable: electric heating, or non-electric heating. Over the past few decades, the major French utility company has been involved and has supported several exploratory programs on envelope airtightness, therefore, the heating system type could be a significant variable. The other variables considered were the floor area, the number of stories and the building age. Chan et al. [20] and McWilliams and Jung [21] found these three variables to be statistically significant when studying the behavior of the NL in the USA. Recorded floor areas were in the range $35.2-255 \mathrm{~m}^{2}$, and most 

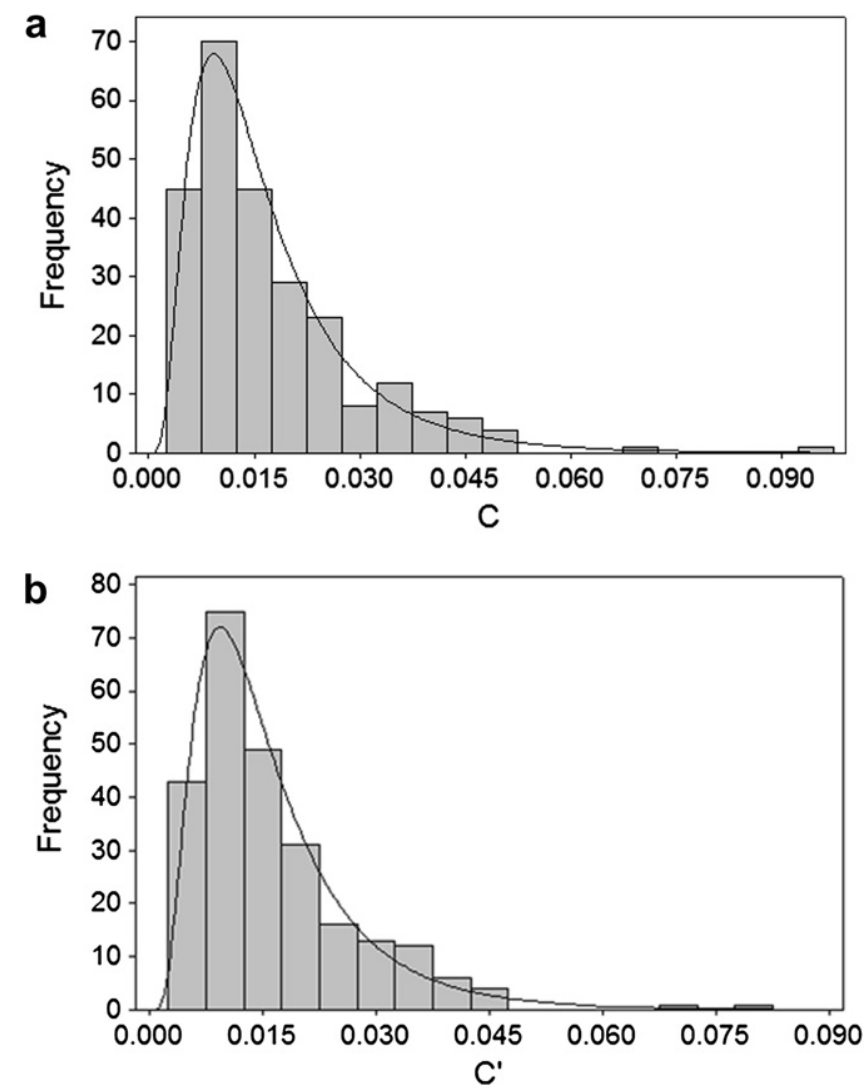

Fig. 2. Histograms and Log normal distributions. a. Distribution of $C$ values. b. Distribution of $\mathrm{C}^{\prime}$ values.

values (85\%) were between 70 and $135 \mathrm{~m}^{2}$, giving a mean area of $96 \mathrm{~m}^{2}$. No floor area data were available for $22.3 \%$ of the dwellings; in these cases we estimated the area as the ratio between the heated volume and the standard height of one floor $(2.5 \mathrm{~m})$. The number of stories ranged between 1 and 3 , and no data were available for $7.6 \%$ of cases. Since very few of the dwellings had three stories $(2.7 \%)$ and there was no significant difference between the airtightness of these dwellings and those with two stories, we considered two possibilities: one story or more than one story.

The age variable is the age of the dwelling at the time of testing. The year in which measurements were taken was recorded for all of the dwellings considered, but the year of construction was only available for $88.4 \%$ of cases. Consequently, the building age at testing could not be obtained for $11.6 \%$ of the dwellings. In addition, the oldest measurement in the database was from 1983, and the oldest year of construction was also 1983. The oldest building age was 9 years, so this value was taken as the limit for the application of the model.

\subsection{Exploratory analysis}

An exploratory analysis using the ANOVA test was conducted to identify possible significant relationships between the building characteristics and the value of $\operatorname{Ln}\left(C^{\prime}\right)$. As explained in the previous section, the following variables were considered: the structure type (ST), the insulation type (IT), the heating system (HS), the building age (Age), the floor area (Area) and the number of stories (NS). The significance of each variable was assessed according to the $P$-value of the F-test, applying a significance level of $5 \%$; that is, $P$-values higher than 0.05 denote no statistical significance between the means of the variable analyzed.
Table 2

$P$-values from the ANOVA test.

\begin{tabular}{lcllll}
\hline Variable & \% data used & Mean $\operatorname{Ln}\left(C^{\prime}\right)$ & & F-test & $P$-value \\
\hline NS & 92.43 & 1 & -4.588 & 46.63 & 0.000 \\
& & 2 & -4.070 & & \\
ST & 93.22 & Heavy & -4.401 & 27.45 & 0.000 \\
& & Light & -3.926 & & \\
IT & 56.28 & Exterior & -3.903 & 3.470 & 0.034 \\
& & Interior & -4.364 & & \\
HS & 51.39 & Integrated & -4.159 & & \\
& & Electric & -4.368 & 3.670 & 0.058 \\
Area & 100.0 & Non-electric & -4.162 & & \\
Age & 88.44 & & & 4.860 & 0.000 \\
\hline
\end{tabular}

The results of the ANOVA test (see Table 2) showed that the following variables have a significant influence on the behavior of $\operatorname{Ln}\left(C^{\prime}\right)$ : NS, ST, Area, Age and IT. No significant differences were observed for $H S$. The mean value of $\operatorname{Ln}(C)$ for single-story dwellings was smaller than the means for dwellings with more than one story, which shows that the buildings with one story were more airtight. In addition, dwellings with light structures were found to be leakier than dwellings with heavy structures, as was expected. The value of $\operatorname{Ln}\left(C^{\prime}\right)$ followed a clear trend and increased in direct proportion to the floor area of the dwelling. This trend was expected, because larger floor areas increase the surface area through which infiltration takes place. We also confirmed that $\operatorname{Ln}\left(C^{\prime}\right)$ increases with building age.

For the IT variable, the highest mean was recorded for exterior insulation, which supports the fact that dwellings with this type of insulation tend to be leakier than others. The mean for interior insulation was the smallest, which shows that dwellings of this type are more airtight. The hypothesis of statistically different means should not be rejected outright, but the statistical significance of this variable in the ANOVA test was lower than that of the other variables. It should also be noted that only $4.4 \%$ of the dwellings had exterior insulation and that no data on insulation type were available for $43.7 \%$ of cases, therefore the lack of representation of the outer insulation could had influenced this result. For the HS, dwellings with non-electric heating were found to be leakier than the others, although this variable was not statistically significant in the ANOVA test.

\section{Model development}

The predictive model was developed from the building variables by applying a stepwise regression using the forward selection procedure [24]. The forward procedure consists in carrying out an initial regression with the most significant variables and then incorporating additional variables one by one; each time a variable is added, the resulting adjusted R-square and the significance of the variable regression coefficient ( $P$-value) were observed. According to the results, we decided whether each variable should be kept. If the adjusted R-square remained at approximately the same value, the variable was discarded, but if it increased significantly, the variable was kept.

The initial model for applying the forward selection is shown in Eq. (6), which considers only the most significant variables (NS, ST, Area and Age). The parameters $\beta_{\text {area }}, \beta_{S T}, \beta_{\text {Age }}$ and $\beta_{N S}$ represent the coefficients for the floor area, the structure type, the building age and the number of stories, respectively. The $S T$ variable takes a value of 0 for heavy structures and 1 for light structures, and NS 
takes a value of 1 for single-story dwellings and 2 for those with more than one story.

$\operatorname{Ln}\left(C^{\prime}\right)=\alpha+\beta_{\text {area }} \cdot$ Area $+\beta_{S T} \cdot S T+\beta_{\text {Age }} \cdot$ Age $+\beta_{N S} \cdot N S$

The second model analyzed considers one more variable, $I T$, as shown in Eq. (7). $\beta_{I T}$ is the coefficient for the insulation type variable, and the $I T$ variable takes a value of 0 for interior or integrated insulation and 1 for exterior insulation.

$$
\operatorname{Ln}\left(C^{\prime}\right)=\alpha+\beta_{\text {area }} \cdot \text { Area }+\beta_{S T} \cdot S T+\beta_{\text {Age }} \cdot \text { Age }+\beta_{N S} \cdot N S+\beta_{I T} \cdot I T
$$

The last model analyzed incorporates the variable $H S$ into Eq. (6), as shown in Eq. (8). The possible values represent electric heating $(H S=0)$ and non-electric heating $(H S=1)$. The heating system was also analyzed because, although its $P$-value was not significant, it was very close to the significance threshold level (0.05). In this equation, $\beta_{H S}$ represents the heating system coefficient.

$$
\begin{aligned}
\operatorname{Ln}\left(C^{\prime}\right)= & \alpha+\beta_{\text {area }} \cdot \text { Area }+\beta_{S T} \cdot S T+\beta_{\text {Age }} \cdot \text { Age }+\beta_{N S} \cdot N S \\
& +\beta_{H S} \cdot H S
\end{aligned}
$$

Table 3 shows the regression results for the three models considered. In the first regression, $80.1 \%$ of the data was used and results were consistent with the findings of the exploratory analysis. All variables showed a high level of significance; however, the adjusted R-square (Adj- $\mathrm{R}^{2}$ ) was not very high, and only $37.47 \%$ of the variability could be explained by this model. For the second model, although Adj- $\mathrm{R}^{2}$ was increased to $40.10 \%$, no statistical significance was found for the IT coefficient $(P$-value $>0.05)$. Therefore, the increase in the value of $\mathrm{Adj}-\mathrm{R}^{2}$ is presumably caused by the decrease in the proportion of data used (due to the absence of data for the IT variable), which falls to $46.61 \%$. As a result, the IT variable was discarded from the model.

The results of the last regression show that all coefficients were statistically significant, including the $H S$ variable, which was not found to be statistically significant in the exploratory analysis. However, the proportion of data used in this regression $(46.21 \%)$ was almost half that of the first regression (80.08\%), due to the absence of data for the HS variable. In addition, the value of $\mathrm{Adj}-\mathrm{R}^{2}$ was the lowest of the three regressions (36.08\%). If we look at the regression coefficients, we can see that when the IT and HS variables were incorporated, the standard error of the coefficients increased with respect to those recorded in regression 1 . This is probably because more data were available for the first regression, which generated a more accurate illustration of the influence of the variables. Therefore, of the models proposed, the linear combination of Eq. (6) appeared to be the best statistical approximation for estimate the airtightness.

\subsection{Adjustment of the age variable}

As discussed in Section 2.1, the maximum building age to which the model can be applied is 9 years. However, most of the current building stock of single-family dwellings is older than 9 years. We therefore adapted the model (Eq. (6)) for houses more than 9 years old by incorporating a new term. The European Standard EN-13465 [25] gives $\mathrm{ACH}_{50}$ values for single-family dwellings as a function of a range of construction years and construction types (airtight, average and leaky), so we were able to capture the effect of age on $\mathrm{ACH}_{50}$. The underlying assumption behind this statement is that the difference in airtightness depending on construction year is more due to the aging than to the construction type. Although the change in the $\mathrm{ACH}_{50}$ is known to be affected by more factors than the aging process only, as it was assumed in this part of the work, this is the best approximation that could be made with the available data. This clearly points out the work needed in this field. The behavior of $\mathrm{ACH}_{50}$ with age was determined by performing a linear regression between the $\mathrm{ACH}_{50}$, the construction type (CT) and the building age, as shown in Eq. (9). The age was estimated as the period from the year in which the standard was introduced (taken to be the tested year, 2004) and the year of construction (taken as the mean of the range of years for which $A C H_{50}$ was reported). The $C T$ variable represents the construction technique, which is defined as airtight $(C T=1)$, average $(C T=2)$ or leaky $(C T=3)$.

$A C H_{50}=\alpha^{\prime}+\beta_{\text {age }}^{\prime} \cdot$ Age $+\beta_{C T}^{\prime} \cdot C T$

Table 4 shows the regression results of Eq. (9), which showed a high correlation. The model explained $93.95 \%$ of the data variability. In addition, all coefficients were found to have a high level of significance, and the change in $A C H_{50}$ due to age was $0.2278 \mathrm{~h}^{-1}$ $( \pm 0.0207)$ per year.

In addition, the earliest year reported in EN-13465 [25] was 1940 , so it was assumed that age had no further effect on airtightness for buildings more than 64 years old. Therefore, the variation of $\mathrm{ACH}_{50}$ between specific ages can be expressed as follows:

$$
\Delta A C H_{50}=\beta_{\text {age }}^{\prime} \cdot\left(\text { Age }_{1}-\text { Age }_{2}\right), \quad \text { Age }_{1}<64
$$

From Eqs. (1) and (2), the change in $A_{C H} H_{50}$ can be expressed in terms of $\Delta C^{\prime}$, as shown in the following expression:

$$
\Delta C^{\prime}=\beta_{\text {age }}^{\prime} \cdot\left(\text { Age }_{1}-\text { Age }_{2}\right) \cdot \text { Area } \cdot 2.5 / 50^{2 / 3}, \quad \text { Age }_{1}<64
$$

To extend the application of the model to dwellings more than 9 years old, Eq. (11) was combined with the expression for predicting $C^{\prime}$ (Eq. (6)), taking a value of 9 for the variable $\mathrm{Age}_{2}$. In this way, we obtained an improved model for estimating the airtightness of

\begin{tabular}{|c|c|c|c|c|c|c|}
\hline \multirow[t]{2}{*}{ Coefficients } & \multicolumn{2}{|l|}{ Regression 1} & \multicolumn{2}{|l|}{ Regression 2} & \multicolumn{2}{|l|}{ Regression 3} \\
\hline & Eq. (6) & $P^{\mathrm{a}}$ & Eq. (7) & $P^{\mathrm{a}}$ & Eq. (8) & $P^{\mathrm{a}}$ \\
\hline$\alpha$ & $-5.6815 \pm 0.1463$ & 0.000 & $-5.7899 \pm 0.2032$ & 0.000 & $-5.6197 \pm 0.2128$ & 0.000 \\
\hline$\beta_{\text {area }}$ & $0.00698 \pm 0.0012$ & 0.000 & $0.01074 \pm 0.0016$ & 0.000 & $0.00652 \pm 0.0017$ & 0.000 \\
\hline$\beta_{\mathrm{ST}}$ & $0.50749 \pm 0.0858$ & 0.000 & $0.3339 \pm 0.1172$ & 0.005 & $0.51184 \pm 0.1139$ & 0.000 \\
\hline$\beta_{\mathrm{NS}}$ & $0.34504 \pm 0.0737$ & 0.000 & $0.2141 \pm 0.1042$ & 0.042 & $0.24792 \pm 0.1013$ & 0.0159 \\
\hline$\beta_{\text {Age }}$ & $0.07837 \pm 0.0192$ & 0.000 & $0.07436 \pm 0.0207$ & 0.000 & $0.08866 \pm 0.0208$ & 0.000 \\
\hline$\beta_{\mathrm{IT}}$ & & & $0.368 \pm 0.2029$ & 0.072 & & \\
\hline$\beta_{\mathrm{HS}}$ & & & & & $0.26398 \pm 0.0975$ & 0.0079 \\
\hline Adj- $R^{2}(\%)$ & $37.47 \%$ & & $40.10 \%$ & & $36.08 \%$ & \\
\hline Data used & $80.08 \%$ & & $46.61 \%$ & & $46.21 \%$ & \\
\hline
\end{tabular}
dwellings with different ages (hereafter called the UPC-CETE model), as shown in Eqs. (12)-(14).

Table 3

Coefficients and adjusted R-squares from each model for estimating $\operatorname{Ln}\left(C^{\prime}\right)$.

${ }^{a}$ P-value. 
Table 4

Coefficients and adjusted R-squares for regression of Eq. (9).

\begin{tabular}{lll}
\hline Coefficients & Eq. (9) & $P^{\mathrm{a}}$ \\
\hline$\alpha$ & $8.60199 \pm 1.2913$ & 0 \\
$\beta_{\text {Age }}^{\prime}$ & $0.22780 \pm 0.0207$ & 0 \\
$\beta^{\prime} C T$ & $4.7 \pm 0.4717$ & 0 \\
Adj- $R^{2}(\%)$ & 93.95 & \\
Data used & 15 & \\
\hline
\end{tabular}

${ }^{a}$ P-value.

For dwellings with Age $\leq 9$ :

$$
\begin{aligned}
C^{\prime}= & \exp \left(-5.6815+0.00698 \cdot \text { Area }+0.50749 \cdot I_{S T}\right. \\
& \left.+0.07837 \cdot \text { Age }+0.34504 \cdot I_{N S}\right)
\end{aligned}
$$

For dwellings with $9<$ Age $\leq 64$ :

$$
\begin{aligned}
C^{\prime}= & \exp \left(-5.6815+0.00698 \cdot \text { Area }+0.50749 \cdot I_{S T}\right. \\
& \left.+0.07837 \cdot 9+0.34504 \cdot I_{N S}\right) \\
& +\left(\text { Area } \cdot \frac{2.5}{50^{2 / 3}} \cdot 0.2278 \cdot(\text { Age }-9)\right)
\end{aligned}
$$

For dwellings with Age > 64:

$$
\begin{aligned}
C^{\prime}= & \exp \left(-5.6815+0.00698 \cdot \text { Area }+0.50749 \cdot I_{S T}\right. \\
& \left.+0.07837 \cdot 9+0.34504 \cdot I_{N S}\right) \\
& +\left(\text { Area } \cdot \frac{2.5}{50^{2 / 3}} \cdot 0.2278 \cdot(64-9)\right)
\end{aligned}
$$

\section{Application to dwellings in Catalonia}

We used our model to estimate the airtightness of Catalan dwellings, $C^{\prime}$, from data on dwelling characteristics per census tract available from the Statistical Institute of Catalonia (IDESCAT) [26]. Census tracts were chosen because they are the smallest population unit from which dwelling characteristics such as floor area, number of stories, and year of construction can be obtained. Catalonia has 5223 census tracts, of which $50.5 \%$ contain more than 10 singlefamily dwellings. The most recent census data is for 2001. The frequencies and cumulative frequency distributions of the variables for Catalonia are shown in Fig. 3. Structure type is not a census variable analyzed by IDESCAT [26]. However, the prevalence of heavy materials in construction in Catalonia was reported by Chavez et al. [27], who analyzed the structural typology of residential houses in Catalonia for three periods: pre-1950, 1950-1970, and post-1970. Therefore, we assumed that all dwellings had a heavy structure.

Once we had obtained the probability distributions for each variable by census tract, we performed a stochastic simulation to obtain the building characteristics for each dwelling [28], since information on the actual characteristics of each dwelling was not available. Data were only simulated for census tracts with more than 10 dwellings, and the number of data simulated was equal to the number of single-family dwellings in the census tract. Several stochastic simulations were performed for a sample of census tracts with different numbers of dwellings, to determine whether the predicted distribution of $C^{\prime}$ varied within simulations. Since not all the predicted distributions of $C^{\prime}$ followed a log-normal distribution, we evaluated the variability between groups by applying the Kruskal-Wallis test, which is a non-parametric method for the analysis of variance in data that do not follow a given probability distribution [29]. The results showed $P$-values higher than 0.05 , which reject the hypothesis of any significant difference between
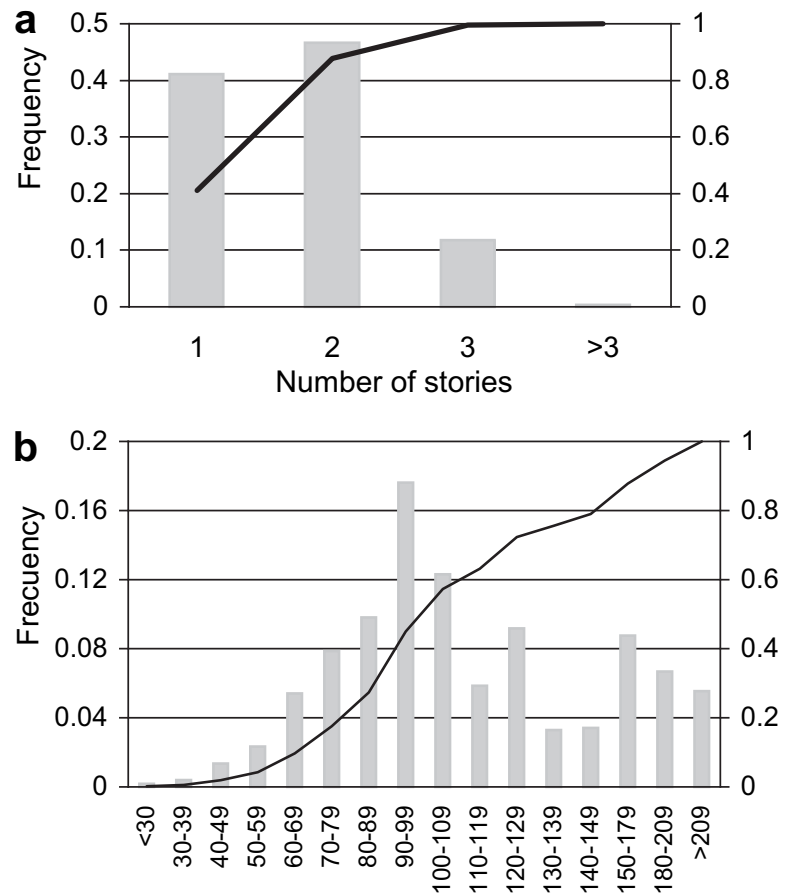

Floor area $\left(\mathrm{m}^{2}\right)$

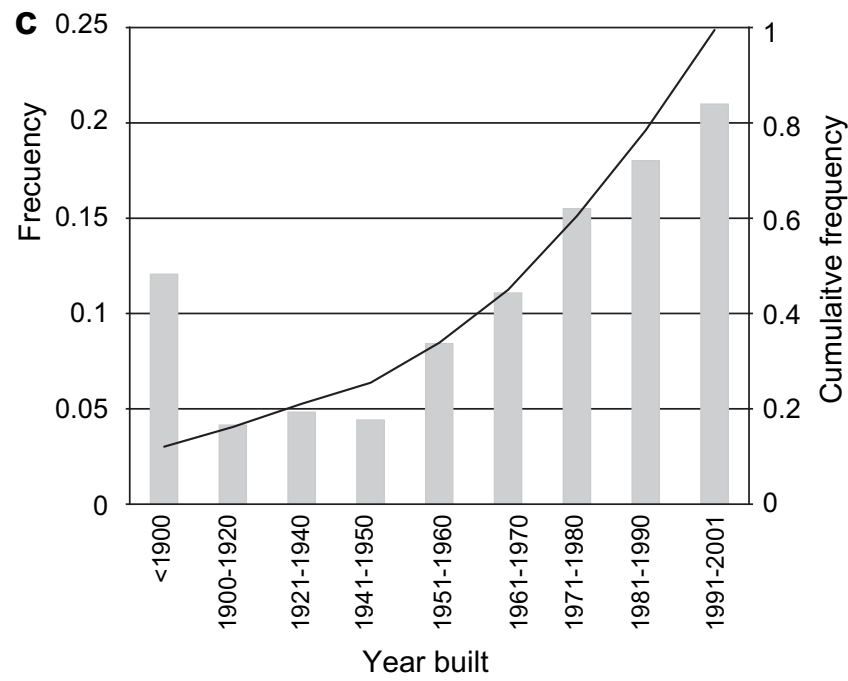

Fig. 3. Frequencies and cumulative frequencies distributions of single-family dwellings in Catalonia. a. Number of stories. b. Floor area. c. Year built.

the medians of $C^{\prime}$ distributions with 95\% confidence for each of the census tracts analyzed.

\subsection{Ventilation model}

Once $C^{\prime}$ had been calculated, the leakage airflow was estimated using the AIM-2 single zone ventilation model. This model uses the $C$ and $n$ of the power law function to characterize the airtightness of the house, so we used $C^{\prime}$ and set $n$ to $2 / 3$. The AIM-2 models differs from other single zone models described in the literature, such as the LBL model [8], in the following ways: it uses the power law to represent the envelope leakage; it distinguishes between houses with crawl spaces or slab-on-grade foundations; and it considers the furnace flue as a separate leakage site. As a result of these differences, described by Walker \& Wilson [9], the AIM-2 gave more 
accurate predictions of ventilation rates under different conditions (i.e. houses with and without furnace flues, wind or stack dominated ventilation), and was reported to have an overall predictive accuracy in the order of $\pm 10 \%$ [4,34]. The main equations of the AIM-2 model are shown below:

$$
\begin{aligned}
& Q=\left(Q_{s}^{1 / n}+Q_{w}^{1 / n}+B_{1} \cdot\left(Q_{s} \cdot Q_{w}\right)^{1 / 2 n}\right)^{n} \\
& Q_{s}=C_{1} \cdot f_{s} \cdot \Delta P_{s}^{n} \\
& \Delta P_{s}=\rho_{\text {out }} \cdot g \cdot H \cdot\left(\left|T_{i}-T_{o}\right| / T_{i}\right) \\
& Q_{w}=C_{1} \cdot f_{w} \cdot \Delta P_{w}^{n} \\
& \Delta P_{w}=\rho_{\text {out }} \cdot\left(S_{w} \cdot v\right)^{2} / 2 \\
& C_{1}=C+C_{\text {flue }} \\
& Y=C_{\text {flue }} / C_{1}
\end{aligned}
$$

The AIM-2 model estimates the infiltration flow $(Q)$ as a combination of the flows induced by the wind effect $\left(Q_{w}\right)$, represented by the wind speed, and the stack effect $\left(Q_{s}\right)$, which reflects the indooroutdoor temperature difference; the value of these flows depends, in turn, on the flow coefficient $\left(C_{1}\right)$, the pressure difference generated by each effect, and the coefficient factors of each effect. The wind factor $\left(f_{\mathrm{w}}\right)$ depends on the presence or absence of a flue and the possibility of slab-on-grade or crawl space foundation. The total shelter factor $\left(S_{\mathrm{w}}\right)$ gives an estimation of the overall shelter provided by the surroundings of the house; it combines the building shelter situation and the flue shelter depending on adjacent obstacles. The stack factor $\left(f_{\mathrm{s}}\right)$ is influenced by the presence of a flue and the height of the dwelling, represented by the number of stories. A detailed description of estimating the stack, wind and wind shelter factors can be found in Walker \& Wilson [9]. To apply this model to single-family dwellings in Catalonia, the following assumptions were made:

- $C$ was taken as the predicted $C^{\prime}$, so $n$ was taken as $2 / 3$.

- Dwellings with more than three stories (less than $0.5 \%$ of the dwellings, see Fig. 3.a) were modeled as three-story buildings.

- Crawl space foundations were not considered. Single-family dwellings in Catalonia are typically constructed using heavy materials, and crawl spaces in this type of construction are very well insulated, so the potential air infiltration through this space is considered negligible.

- The presence of a flue was assumed for all dwellings, as this is a typical construction feature in single-family dwellings in Catalonia.

- The relation between the flue flow coefficient $\left(C_{\text {flue }}\right)$ and the total flow coefficient $\left(C_{1}\right), Y$ (Eq. (21)) was assumed to be 0.2 , which is a typical value [9].

- A heavily shielded terrain, many large obstructions within one building height [9] was assumed as the shelter situation for the building. The flue was considered unsheltered.

- All infiltration was assumed to take place through the walls and the flue. Infiltration through floors and ceilings was not considered, since the techniques and materials used in residential constructions in Catalonia ensure that these components are very airtight.

- The flue outlet was $1.5 \mathrm{~m}$ above the upper ceiling.

- Each story was $2.5 \mathrm{~m}$ high.

\subsection{Meteorological conditions}

In addition to $C^{\prime}$, pressure difference driven forces (Eqs. (17) and (19)) from wind speed $\left(\Delta P_{\mathrm{w}}\right)$ and stack effect $\left(\Delta P_{\mathrm{s}}\right)$ are also needed to compute the infiltration flow. Average and extreme conditions for each season were assessed. Wind speed data were taken from the monthly average and average maximum records of meteorological stations [30]. Since the stations are located at different altitudes, all records were corrected to $3 \mathrm{~m}$ using the correction method proposed by Sherman \& Grimsrud [8]. The outdoor temperature was taken directly from a geographical information system, which contains several layers showing the distribution of average temperatures, average maximums and average minimums per season for Catalonia [31]. To calculate the temperature difference, an indoor temperature of $20{ }^{\circ} \mathrm{C}$ was assumed for winter, spring and autumn and a temperature of $25{ }^{\circ} \mathrm{C}$ for summer.

To evaluate average conditions, the outdoor temperature was simply taken as the average temperature, whereas to evaluate extreme conditions it was taken as the average minimum temperature for winter, spring and autumn and the average maximum temperature for summer, since these combinations gave the largest temperature difference. Outdoor air density is also needed to calculate the pressure differences (Eqs. 17 and 19). The air density was estimated according to outdoor temperature, assuming a pressure of 1 atmosphere and a relative humidity of $50 \%$ in all cases. Once the pressure differences had been estimated, the airflow induced by each effect was calculated using Eqs. 16 and 18. These airflows were then combined using Eq. (15) to estimate the leakage airflow. This flow divided by the dwelling volume - which is the product of the floor area and the standard height of one story, as shown in Eq. (22) - gives an estimation of the $A C H$.

$A C H=Q \cdot 3600 / 2.5 \cdot$ Area

\subsection{Other models}

Our predictions should be compared with experimental data to verify the performance of the proposed model. However, since no experimental airtightness or $A C H$ data are available for Catalonia, we compared the predicted values of airtightness and $A C H$ with those obtained using the LBNL airtightness predictive model. We also compared $A C H$ predictions with the corresponding values given by the TNO equations.

\subsubsection{LBNL airtightness predictive model}

The LBNL airtightness predictive model, developed by McWilliams \& Jung [21], was also used to estimate the airtightness distribution of single-family dwellings in Catalonia. This model, presented in Eq. (23), predicts a value of NL as a function of climate zone $(C Z)$, floor area (size), height $\left(N_{\text {story }}\right)$, age (Age), possibility of floor leakage $\left(P_{\text {floor }}\right)$, possibility of participation in an energy-efficiency program $\left(P_{\mathrm{Eff}}\right)$, and possibility of being a low-income house $\left(P_{\mathrm{LI}}\right)$. The $P$ parameters $\left(P_{\mathrm{LI}}, P_{\mathrm{Floor}}\right.$ and $\left.P_{\mathrm{Eff}}\right)$ reflect the possibility that the house meets the given condition, taking a value of 1 if the condition is met and a value of 0 if it is not. The values for the other parameters are shown in Table 5 , where the $N L_{C Z}$ parameter depends on the climate zone in which the house is located. McWilliams \& Jung [21] consider the climate zones "humid", "cold", "dry" and "Alaska", based on combinations of the climate zones defined by the Building Science Corporation, which classifies zones according to annual precipitation and heating degree days [32]. When the same criteria were applied to Catalonia, only humid and dry climates were found, as shown in Fig. 4. 
Table 5

Parameters in the LBNL predictive model [21].

\begin{tabular}{llllll}
\hline$N L C z$ & Value & Parameter & Value & Parameter & Value \\
\hline$N L_{\text {Alaska }}$ & 0.36 & $\phi_{\text {height }}$ & 1.156 & $\phi_{\text {Floor }}$ & 1.08 \\
$N L_{\text {Cold }}$ & 0.53 & $\phi_{\varepsilon}$ & 0.598 & $\phi_{\text {LI }}$ & 2.45 \\
$N L_{\text {Humid }}$ & 0.35 & $\phi_{\text {Age }}$ & 1.0118 & $\phi_{\text {LI,Age }}$ & 0.9942 \\
$N L_{\text {Dry }}$ & 0.61 & $\phi_{\text {Area }}$ & 0.841 & $\phi_{\text {LI,Area }}$ & 0.775 \\
\hline
\end{tabular}

$N L=N L_{C Z} \cdot \phi_{\text {area }}^{\text {size }-1} \cdot \phi_{\text {height }}^{N_{\text {story }}-1} \cdot \phi_{\varepsilon}^{P_{\text {eff }}} \cdot \phi_{\text {age }}^{\text {age }} \cdot \phi_{\text {floor }}^{P_{\text {floor }}} \cdot\left(\phi_{\text {LI, age }}^{\text {age }} \cdot \phi_{\text {LI, area }}^{\text {size }-1} \cdot \phi_{L I}\right)^{P_{L I}}$

We did not consider the possibility of floor leakage $\left(P_{\text {Floor }}=0\right)$ when applying this model to Catalan dwellings, as we also neglect this possibility when using the AIM-2 model. The possibility of participation in an energy-efficiency program and the possibility of classification as a low-income house were also excluded $\left(P_{\mathrm{Eff}}=P_{\mathrm{LI}}=0\right)$, since our aim was to assess the airtightness of typical houses. The other variables used when applying the model were those obtained by the stochastic simulation. $N L$ is a parameter commonly used in the USA to describe the airtightness of a dwelling. It is defined in terms of equivalent leakage area (ELA), as shown in Eq. (24), which represents the area of an opening that, if exposed to the same pressure difference as the house, would lead to the same leakage airflow, based on the Bernoulli equation (Eq. (25)) [4].

$$
\begin{aligned}
& N L=1000(\text { ELA/Area })\left(N_{\text {story }}\right)^{0.3} \\
& Q=C_{D} \cdot E L A \cdot \sqrt{2 \cdot \Delta P / \rho}
\end{aligned}
$$

The relationship between $C^{\prime}$ and $E L A$, obtained from Eq. (1) and Eq. (25), can be expressed as shown in Eq. (26), assuming a discharge coefficient of $1\left(C_{D}=1\right)$, a pressure difference of $4 \mathrm{~Pa}(\Delta P=4)$ and the air density at standard conditions $\left(\rho=1.2 \mathrm{~kg} / \mathrm{m}^{3}\right.$ at $\left.20^{\circ} \mathrm{C}\right)$.

$$
C^{\prime}=E L A /(4)^{0.67-0.5} \sqrt{2 / 1.2}
$$

To estimate the infiltration airflow and $A C H$ distribution, the AIM-2 model (Eqs. 15-21) was also applied to the predicted $C^{\prime}$ obtained with the LBNL airtightness model.

\subsubsection{TNO empirical equations}

As described in the introduction section, the Netherlands Organisation for Applied Scientific Research [10] reported two empirical correlations that captured the dependence of $A C H$ on wind speed in high (Eq. (27)) and low-rise buildings (Eq. (28)). To compare the $A C H$ distributions obtained with the UPC-CETE and LBNL airtightness models, combined with the AIM-2 ventilation model, the low-rise buildings expression was used to calculate $A C H$ distribution across Catalonia as a function of the wind speed distribution by season.

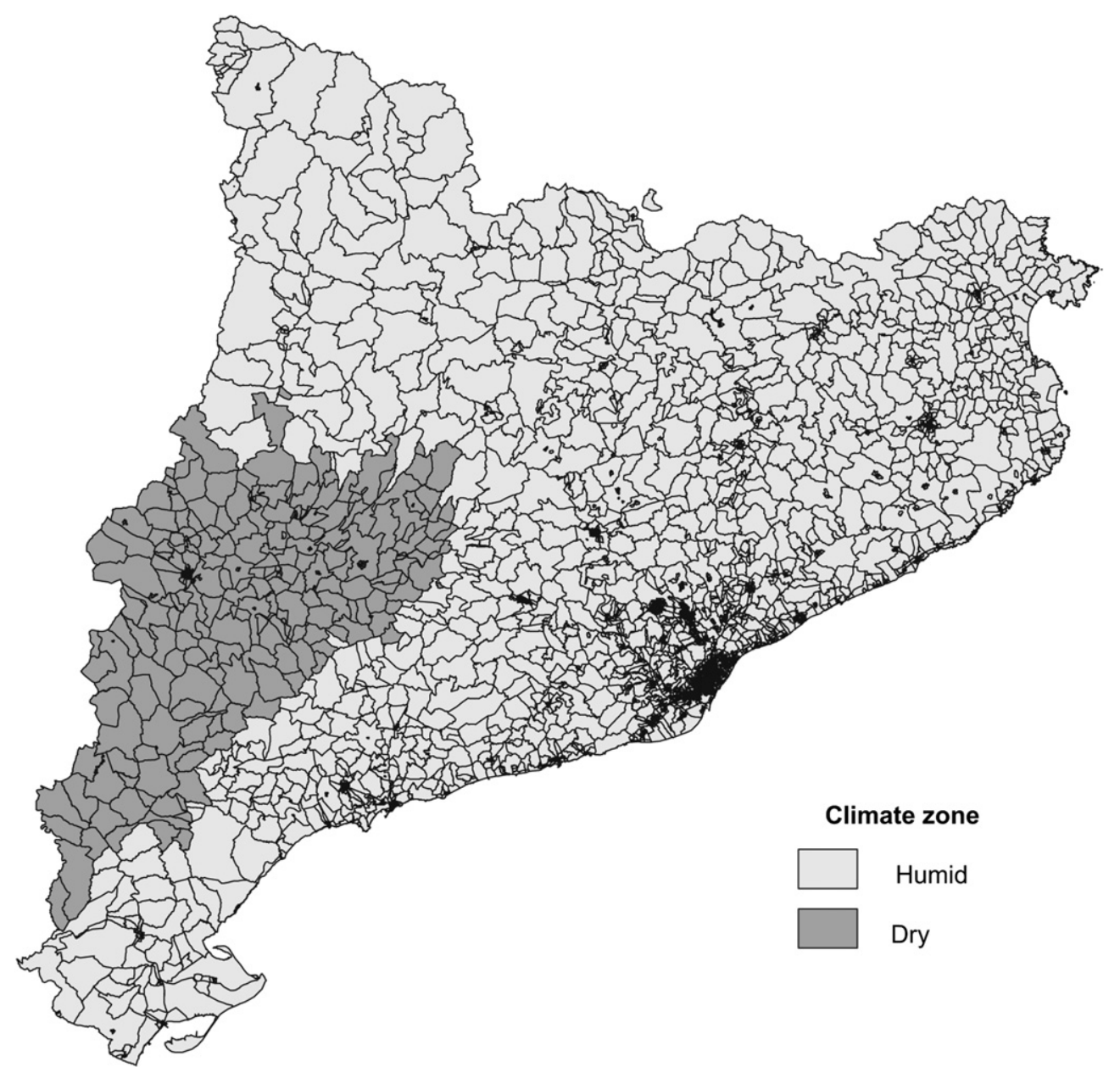

Fig. 4. Catalonian climate zones according to the Building Science Corporation. 
High buildings : $\mathrm{ACH}=0.1+0.04 \cdot v$

Low buildings : $\mathrm{ACH}=0.1+0.14 \cdot v$

\subsection{Results and discussion}

The predicted distribution of $C^{\prime}$ obtained with the UPC-CETE model for Catalonia is shown in Fig. 5. If we compare this value with empirical data on the distribution for French houses (Fig. 2), we can see that the predicted $C^{\prime}$ is higher for Catalan dwellings. This result was expected, because more than $90 \%$ of the Catalan dwellings considered were more than 9 years old.

The ELA distributions obtained with the UPC-CETE model (Eqs. (12)-(14)) and the LBNL airtightness model (Eq. (23)) are shown in Fig. 6. ELAs predicted with the UPC-CETE model were slightly smaller than those estimated with the LBNL airtightness model, as was expected, because lower $A C H$ had been reported for French dwellings than for USA dwellings [15]. Even though, there are no data for making a direct comparison with dwellings in Catalonia. Chan et al. [20] reported that typical values of ELA for single-family dwellings in the USA range from $0.04 \mathrm{~m}^{2}$ (tight) to $0.3 \mathrm{~m}^{2}$ (leaky). If we take these as reference values, we can see that the predicted ELAs fall into the same range but are closer to the lower value. Under French regulations, which stipulate that airtightness must be expressed in terms of $I_{4}$, the value used (so-called reference value) for the notional single-family dwelling in the French energy performance regulation is $0.8 \mathrm{~m}^{3} /\left(\mathrm{h} \mathrm{m}^{2}\right)$. Eqs. (3) and (25) were used to calculate this value in terms of ELA for a house with a floor area of $100 \mathrm{~m}^{2}$, a $C_{D}$ of $1, \rho=1.2 \mathrm{~kg} / \mathrm{m}^{3}$, and a $V / S_{\mathrm{f}}$ of $1.4 \mathrm{~m}^{3} / \mathrm{m}^{2}$, which is typical of French dwellings [18]. The corresponding ELA value was $0.0153 \mathrm{~m}^{2}$, which is much lower than the predicted ELAs.

The results for $A C H$ distribution within seasons using the UPCCETE model are shown in Fig. 7, those predicted with the LBNL airtightness model are shown in Fig. 8, and those predicted with the TNO empirical equations are shown in Fig. 9. Since the AIM-2 model was applied to the UPC-CETE and LBNL airtightness predictions to estimate the $A C H$, the difference between the $A C H$ distributions given by the two models followed the same pattern as the difference between predicted ELAs (see Fig. 6). The biggest differences were found in cumulative frequencies lower than $20 \%$ and higher than $80 \%$, whereas those between the 20th and 80th percentiles were very close and showed differences of less tha $10 \%$. The $A C H$ distributions obtained with the TNO empirical equations show different behavior to those obtained with the UPC-CETE and LBNL airtightness models, mainly in the case of extreme average meteorological conditions. This difference is not surprising because

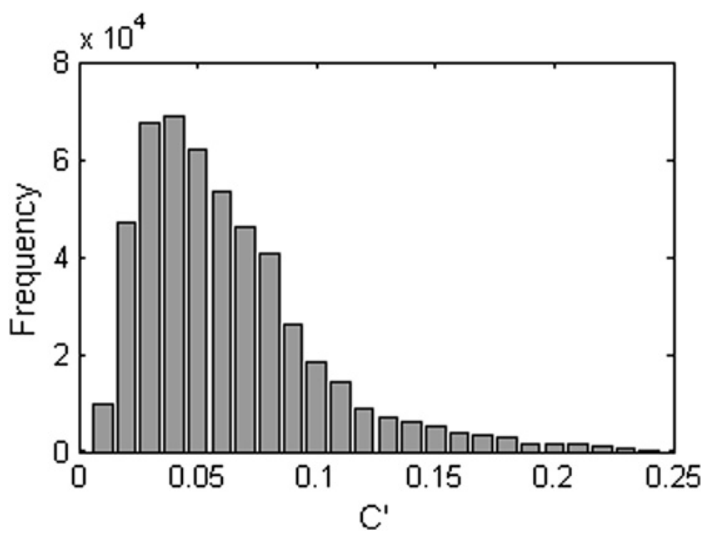

Fig. 5. Histogram of $\mathrm{C}^{\prime}$ distribution of Catalonian dwellings.

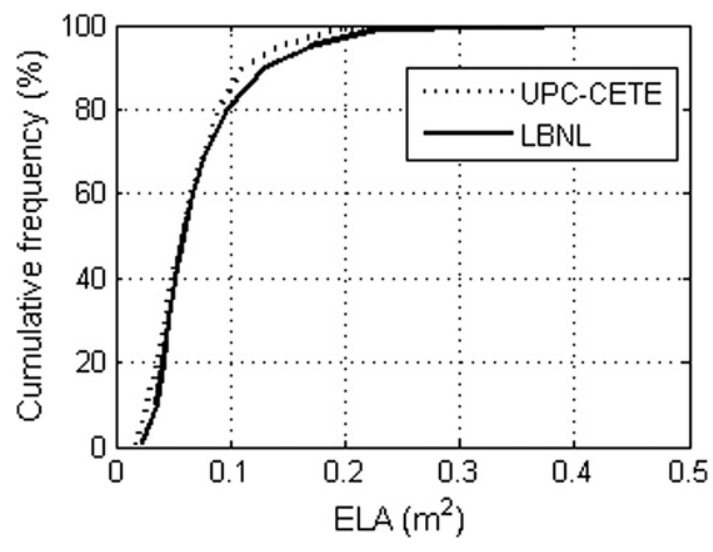

Fig. 6. ELA distribution of Catalonian single-family dwellings.

the empirical equation only takes into account the variability in wind speed to estimate the $\mathrm{ACH}$ and does not consider house airtightness or stack effect.

ACHs predicted with the UPC-CETE model are generally lower than those predicted with the LBNL airtightness model. If we analyze $A C H$ distribution by season, the highest values are recorded in winter due to the extreme meteorological conditions during this season. The lowest values of $A C H$ under average meteorological conditions are recorded in summer, and the lowest values under extreme average meteorological conditions are recorded in autumn.

It can be seen from the results that, under average conditions, in summer and autumn $80 \%$ of dwellings showed $A C H$ s lower than
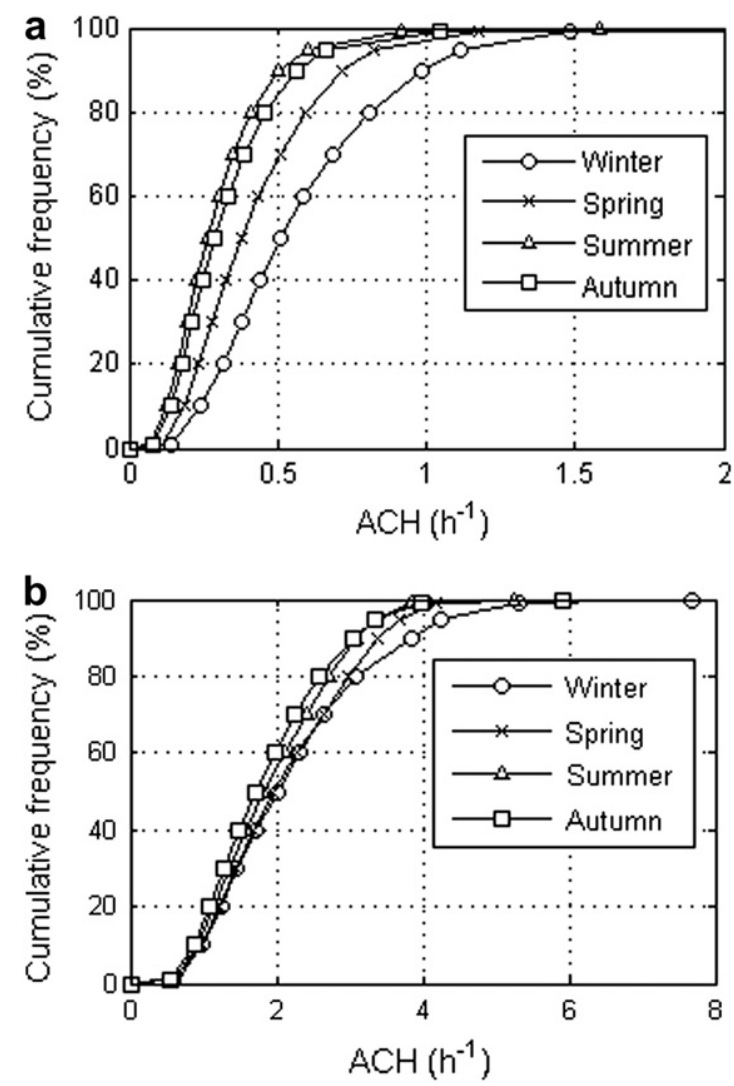

Fig. 7. ACH distribution of Catalonian single-family dwellings applying the UPC-CETE model. a. Average meteorological conditions. b. Extreme average meteorological conditions. 

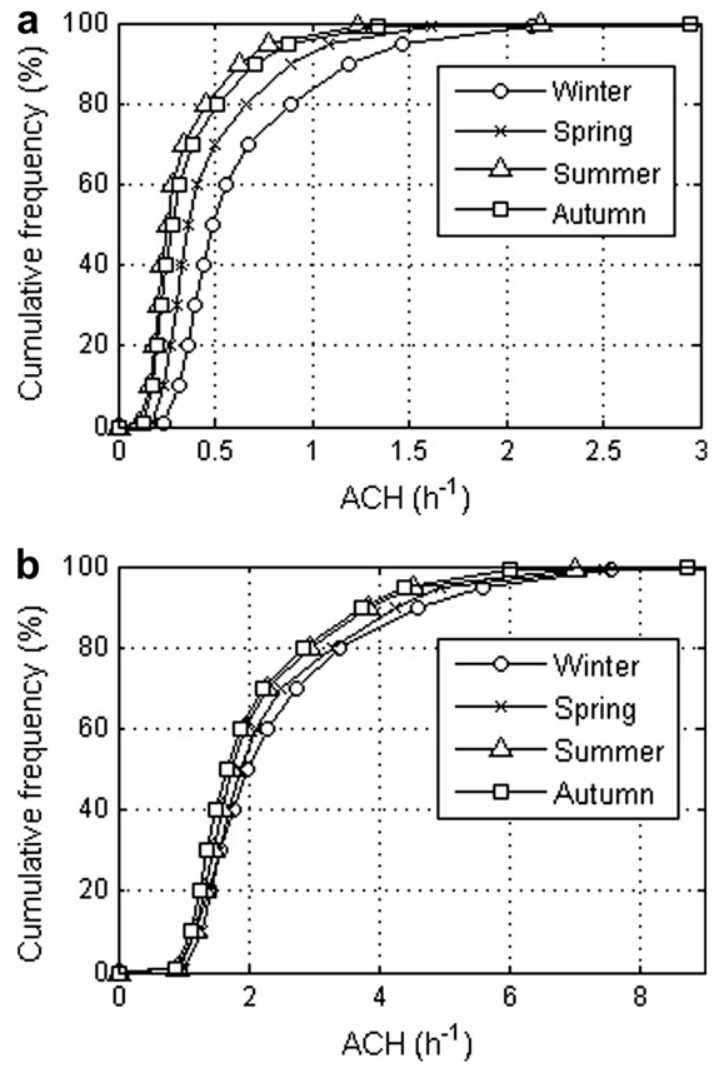

Fig. 8. ACH distribution of Catalonian single-family dwellings applying the LBNL model. a. Average meteorological conditions. b. Extreme average meteorological conditions.

$0.5 \mathrm{~h}^{-1}$ for both the UPC-CETE and the LBNL airtightness models, whereas in spring and winter $70 \%$ and $50 \%$ of dwellings showed ACHs lower than $0.5 \mathrm{~h}^{-1}$, respectively. If we compare the results with residential $A C H$ distribution by season in the USA $[12,13]$, where $A C H$ s lower than $0.5 \mathrm{~h}^{-1}$ were reported for $60 \%$ of dwellings in winter, $50 \%$ in spring, $80 \%$ in autumn and only $25 \%$ in summer, we can see that similar values were obtained in autumn and that the biggest difference was recorded in summer. Under extreme conditions, only $10 \%$ of dwellings showed $A C H$ s lower than $1 \mathrm{~h}^{-1}$ in all seasons, whereas $90 \%$ of dwellings in summer and autumn and $80 \%$ of dwellings in winter and spring showed ACHs below $3 \mathrm{~h}^{-1}$.

Currently, Catalonian Government assumes a constant $A C H$ of $2 \mathrm{~h}^{-1}$ to perform indoor concentration calculations in relation to the estimation of shelter-in-place effectiveness and evacuation radius in the event of a toxic gas release. This value, assumed by Catalonian Government as a conservative $A C H$, has some drawbacks regarding the results obtained in this work. In relation to the $A C H$ distribution obtained using average meteorological conditions (Figs. 7a and 8a), an $A C H$ of $2 \mathrm{~h}^{-1}$ is effectively a conservative value that introduces an overestimation on the $A C H$ in more than $90 \%$ of the dwellings. Therefore shelter-in-place effectiveness estimated using this value would be underestimated and evacuation radius overestimated, which result in unnecessary efforts. On the other hand, if a toxic gas release takes place when meteorological conditions are extreme, an $A C H$ of $2 \mathrm{~h}^{-1}$ would represent the median value of the $A C H$ distribution under these meteorological conditions (Figs. $7 \mathrm{~b}$ and $8 \mathrm{~b}$ ), meaning that the evacuation radius would be underestimated and a fraction of the population could be left in danger. In addition, this situation of extreme conditions, especially high wind speeds, should be handled very carefully since as reported by Guyot et al. [33], although the pollutant dilutes faster
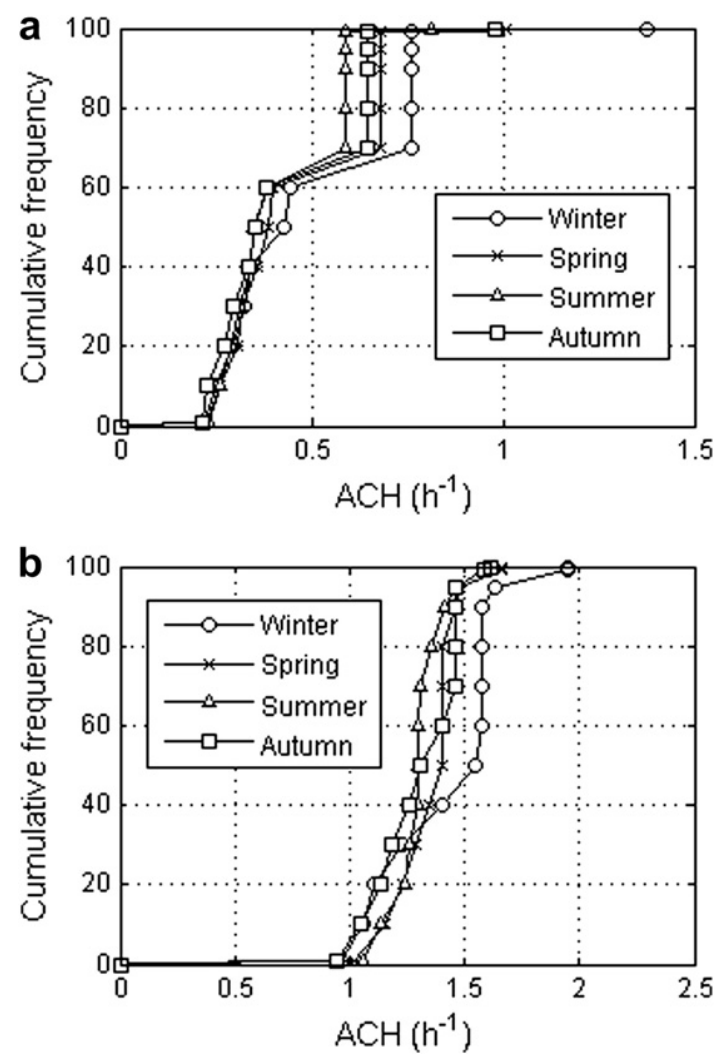

Fig. 9. ACH distribution of Catalonian single-family dwellings applying the empirical equations of the TNO. a. Average meteorological conditions. b. Extreme average meteorological conditions.

with increasing wind speed, the resulting dose inside the shelter could increase due to the effect of the wind over the $A C H$, accelerating the toxic gas transfer to the indoor. Thus, a better procedure to estimate the shelter-in-place effectiveness and the evacuation radius should include an appropriate determination of the outdoor concentration for the specific meteorological conditions, especially high wind speeds, and the $A C H$ distribution for the affected area under these meteorological conditions as also proposed by Chan et al. [2], instead of assuming a constant $A C H$ for all the dwellings inside the affected area.

During a shelter-in-place situation, people are advised to close all intentional openings such as doors and windows. However, people will often forget, or be unable to, seal the fireplace and extraction ducts in kitchen and bathrooms. Therefore, the presence or absence of a flue should be taken into account in the estimation of the air infiltration rate to assess shelter-in-place effectiveness, as is the case of the AIM-2 model used here. This parameter could affect the $A C H$ considerably, mainly in the presence of large temperature differences and high wind speeds, as discussed by Walker \& Wilson [9].

\section{Conclusions}

We have developed a statistical model for predicting the airtightness of single-family dwellings in France and Spain as a function of building features. In the case of Catalonia, for which no experimental data regarding airtightness or air exchange rates are available, this model is the first proposal for estimating the airtightness distribution of single-family dwellings, which could be used by Catalonian Government to better assess the relevance of the $A C H$ assumption. In the event of a toxic gas release, our model 
could be used by emergency managers together with the outdoor concentration, depending on meteorological conditions, to estimate the indoor concentration and consequently the exposure dose, the shelter-in-place effectiveness and the intervention zones (i.e. evacuation zones). The zones where the specific pollutant gas threshold doses are exceeded.

The values of $C^{\prime}$ and $A C H$ calculated for Catalonia correspond to distributions obtained using the best sources of information available, such as the CETE air leakage database, statistical data on the characteristics of dwellings in Catalonia, and average meteorological conditions for all seasons. However, empirical measurements of airtightness and air infiltration, which can be obtained using the pressurization method and tracer gas techniques, respectively, would greatly improve our understanding of the overall airtightness of single-family dwellings in Catalonia. Additional experimental data could also be used to validate and/or improve the model presented here.

\section{Acknowledgements}

The authors thank the Autonomous Government of Catalonia for financial support (project No. 2009SGR1118). M.I. Montoya is grateful to the Spanish Ministry of Education and Science for the award of an FPU fellowship.

\section{References}

[1] PLASEQCAT. Pla d'Emergència Exterior del Sector Químic de Catalunya (Emergency Plan for the Chemical Sector at Catalonia). Generalitat de Catalunya, Direcció General de Protecció Civil. Available at, http://www.gencat.cat/ interior/emergencies/plans/quimic/emergencia/index.htm; 2007.

[2] Chan WR, Nazaroff WW, Price PN, Gadgil AJ. Effectiveness of urban shelter-inplace-II: residential districts. Atmospheric Environment 2007;41:7082-95.

[3] Montoya MI, Planas E, Casal J. A comparative analysis of mathematical models for relating indoor and outdoor toxic gas concentrations in accidental releases. Journal of Loss Prevention in the Process Industries 2009;22(4):381-91.

[4] Handbook fundamentals. SI Ed. Atlanta, GA: ASHRAE; 2005 [Chapter 27]

[5] Erhorn H, Erhorn-Kluttig H, Carrié FR. Airtightness for high performance buildings. In: Proceedings of the 29th AIVC Conference 2008:2:25-30 [Kyoto, JP]

[6] Sherman M. Air leakage of US homes. In: Proceedings of the 29th AIVC Conference 2008;3:333-340 [Kyoto, JP].

[7] ASTM Standard E741-00. Test method for determining air change in a single zone by means of a tracer gas dilution. Philadelphia, PA: American Society for Testing and Materials; 2000.

[8] Sherman MH, Grimsrud DT. Infiltration pressurization correlation: simplified physical modeling. Ashrae Transactions 1980;86(2):778-807.

[9] Walker IS, Wilson DJ. Field validation of algebraic equations for stack and wind driven air infiltration calculations. ASHRAE HVAC\&R Research Journal 1998;4(2):119-39.

[10] Methods for the determination of possible damage to people and objects resulting from the release of hazardous materials. CPR 16E. Protection against toxic substances by remaining indoors. The Netherlands Organisation for Applied Scientific Research (TNO); 1989.

[11] Engelmann RJ. Sheltering effectiveness against plutonium provided by buildings. Atmospheric Environment 1992;26A(11):2037-44.

[12] Murray DM, Burmaster DE. Residential air exchange rates in the United States: Empirical and estimated parametric distribution by season and climatic region. Risk Analysis 1995;15(4):459-65.
[13] Angell W, Grimsrud DT, Lee H. Survey and critical review of scientific literature on indoor air quality. ventilation, and building-related health effects in residences. residential ventilation (Chapter 6)Available at. USEPA, http://mniaa. org/iaqresidential.html; 2004.

[14] Sherman MH, Dickerhoff D. Air-tightness of US. dwellings. ASHRAE Transactions 1998;104(2):1359-67.

[15] Orme M, Wliddament M, Wilson A. An analysis and data summary of the AIVC numerical database. air infiltration and ventilation centre, vol. 44. Technical Note; 1998.

[16] Litvak A, Guillot K, Kilberger M, Boze D. Airtightness of French dwellings: Results from field measurement studies. In: Proceedings 21st AIVC annual conference, "Innovations in ventilation technology", 26-29 September 2000; paper 60 [The Hauge, NL].

[17] Litvak A, Kilberger M, Guillot K. Field measurement results of the airtightness of 64 French dwellings. In: Proceedings of Roomvent 2000, "Air distribution in rooms: Ventilation for health and sustainable environment"; 9-12 July 2000; 2: 1093-1098 [Oxford, UK].

[18] Carrié R, Jobert R, Fournier M, Berthault S. Perméabilité à l'air de l'enveloppe des bâtiments. Généralités et sensibilisation. CETE de Lyon. Available at, http://www.cete-lyon.equipement.gouv.fr/home_fichiers/domainesactivite/ auhc/generalites_et_sensibilisationv2.32-600dpi.pdf; 2006.

[19] Sherman M, Chan WR. Building airtightness: research and practice. Lawrence Berkeley Laboratory Report No. 53356; 2004.

[20] Chan WR, Nazaroff WW, Price PN, Sohn MD, Gadgil AJ. Analyzing a database of residential air leakage in the United States. Atmospheric Environment 2005;39:3445-55.

[21] McWilliams J, Jung M. Development of a mathematical air-leakage model from measured data. Lawrence Berkeley Laboratory Report: No. 59041; 2006.

[22] European standard NF EN 13829:2001. Thermal performance of buildings. Determination of air permeability of buildings. Fan pressurization method. January; 2001.

[23] Sherman MH. Superposition in infiltration modeling. Indoor Air 1992;2: 101-14.

[24] Draper NR, Smith H. Applied regression analysis. Wiley Series in Probability and Statistics. 3rd ed. John Wiley \& Sons; 1998.

[25] European standard NF EN 13465:2004. Ventilation for buildings: calculation methods for the determination of air flow rates in dwellings. 2004.

[26] IDESCAT. Statistical institute of Catalonia. Available at, http://www.idescat.cat.

[27] Chávez J, Goula X, Roca A, Mañá F, Presmanes JA, López-Arroyo A. Escenarios de daños sísmicos en Cataluña (Seismic damage scenarios in Catalonia). 1er Congreso Nacional de Ingeniería Sísmica, Murcia; 1999.

[28] Heath MT. Scientific computing: an introductory survey. Chapter 13 - random numbers and stochastic simulation. Available at, http://www.cse.uiuc.edu/ heath/scicomp/notes/chap13 8up.pdf; 2002.

[29] Montgomery DC, Runger GC. Applied statistics and probability for engineers. 4 th ed. John Wiley \& Sons, Inc; 2007.

[30] Servei Meteorològic de Catalunya (Meteorological Service of Catalonia). Anuari de dades meteorològiques (Yearbook of meteorological data). Available at, http://www.meteocat.com/marcs/marc_clima.html; 2003.

[31] Servei Meteorologic de Catalunya (Meteorological Service of Catalonia). Atlas Climático Digital de Catalunya (Digital Climatic Atlas of Catalonia). Available at, http://mediambient.gencat.net/cat/el_departament/cartografia/ fitxes/tmensual.jsp?Compo; 2001.

[32] Building Science Consulting. Consulted in April 18th of 2007. Available at, http://www.buildingscienceconsulting.com/designsthatwork/hygro-thermal. htm.

[33] Guyot G, Carrié FR, Limoges D, Goyet R, Salager J. Éléments pour mettre en oeuvre une stratégie de confinement en cas de pollution atmosphérique accidentelle (Elements to implement a shelter in place strategy in case of accidental pollution). Centre d'Etudes techniques de l'Equipement de Lyon (Cete de Lyon). Available at, http://www.cetelyon.equipement.gouv.fr/IMG/ pdf/Mise_en_oeuvre_strategie_de_confinement_19-09-2008_cle7a4d67.pdf; 2008.

[34] Wang W, Beausoleil-Morrison I, Reardon J. Evaluation of the Alberta air infiltration model using measurements and inter-model comparisons. Building and Environement 2009;44(2):309-18. 